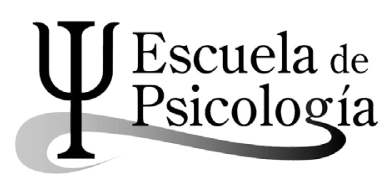

Wímb lu, Rev. electrónica de estudiantes Esc. de psicología, Univ. de Costa Rica. 9 (2): 61-70, 2014 / ISSN: 1659-2107

\title{
UN RECUENTO DE ASPECTOS SOBRE EL ENVEJECER: A PROPÓSITO DE LA PELÍCULA INOCENCIA
}

A review of the ageing process aspects: about the film Innocence

Paola Palma*

Resumen: En el presente ensayo se ofrecerá un estudio de caso tomando como referencia la película Inocencia, dirigida por Paul Cox en el año 2000. Los segmentos de este estudio estarán orientados por tres preguntas fundamentales: 1 . ¿Cómo se vive en el envejecer? 2. ¿Cómo se vive la muerte? y 3. ¿Cómo se vive la sexualidad? Esta reflexión ha permitido desarticular algunas falsas creencias en torno a la sexualidad y la vivencia de esta etapa. A la vez que los aspectos enunciados se ejemplifican con escenas de la pelicula.

Palabras clave: Muerte, sexualidad, proceso de envejecer, tercera edad.

Abstract: In the following essay, a case study will be provided by reference to the movie Innocence, directed by Paul Cox in the year 2000. The segments of this study will be guided by three fundamental questions: How the ageing process is experienced? How death is experienced? How sexuality is experienced? This reflection has allowed to break up some false beliefs about sexuality and the experience of this stage. The aspects mentioned are exemplified with escenes from the movie.

Key Words: Death, sexuality, ageing process, elderly people.

* Estudiante de psicología, Universidad de Costa Rica.

Correo electrónico: paola21palma@gmail.com.

Recepción: 23/6/2014 Aceptación: 20/10/2014 


\section{Sobre la vivencia del envejecer}

"Mientras tengas vigor físico disfrutadlo;
cuando haya desaparecido no lo lamentéis"

(Cicerón)

Existe una tendencia a visualizar la vejez como una etapa cargada de aspectos negativos, lo cual es producto de un proceso de larga data histórica, sin embargo se ha de tener en cuenta, para el desarrollo de este apartado, el lograr una definición no negativa de dicha etapa. Un primer acercamiento a qué es el envejecer proporciona una definición sencilla: "el envejecimiento es un proceso adverso intrínseco, universal y progresivo que ocurre con el tiempo en todo ser vivo a consecuencia de su interacción genética con el medio ambiente" (Fernández González, 2008, p. 235).

Antes de continuar con el análisis se ofrecerá un pequeño resumen de la trama de la película. Se trata de una pareja de adultos mayores (Claire y John), los cuales están en una etapa de rutina en su matrimonio, muy lejos de mostrarse afecto. Durante este momento, Claire se reencuentra con su amante de juventud: Andreas; en su momento esta pareja fue separada por el padre del, entonces, joven Andreas. Claire y Andreas reviven su amorío ante la mirada, primero incredula y depués celosa, del marido de esta. Durante el desarrollo de la película, nos enteramos de que Andreas está enfermo: tiene cáncer, durante su decisión de no someterse a ningún tratamiento, reflexiona mucho acerca de la muerte. Asimismo, Claire presenta una enfermedad cardíaca de la que muere hacia al final de la película, después de haber disfrutado de la posibilidad de revivir sentimientos de amor y pasión gracias a su reencuentro con Andreas.

Volviendo a la definición de envejecimiento dada por Fernández González (2008), se puede entrever en ella un claro tinte biologicista, es decir se está viendo el proceso como el producto de la interacción genética de un ser vivo (no sujeto) con su ambiente. Esta definición no está tomando en cuenta los aspectos psicosociales que atañen a toda etapa de la vida de los seres humanos.

La definición de Fernández González (2008) es insuficiente para poder explicar el proceso que experimentan los personajes de la película Inocencia, pues no toma en cuenta los aspectos de la historia personal de cada individuo y cómo estos tienen una incidencia directa en cómo se vivirá el proceso de envejecer. Estos aspectos de la historia personal involucran todas las experiencias vividas, lo psicoafectivo, lo laboral, lo familiar, etc. Pese a lo anterior, Fernández González (2008) tiene un gran atino al afirmar que:

El envejecimiento no es una enfermedad y hay que distinguirlo de las causas de muerte por edad avanzada: padecimientos cardiovasculares, ictus cerebral, cáncer, entre otros, cuya prevención ha demostrado que la expectativa de vida ha aumentado más de quince años (p. 235). 
El envejecimiento no es una enfermedad, es el atino de la cita, pero en ese caso, ¿cómo se define? ¿Cuáles son sus características? ¿Qué distingue esta etapa de las otras etapas de desarrollo? Tomando como referencia a los personajes Andreas y Claire de la película Inocencia, podríamos aseverar que, por la vivencia que ellos dos experimentan, el proceso de envejecer puede traer nuevas experiencias, nuevos conocimientos, nuevas afectividades para la persona adulta que las quiera experimentar, se puede notar en estos personajes un acercamiento al arte que los dota de una sensibilidad hacia la vida, por ejemplo, Andreas al tocar el órgano y Claire al recitar poesía en francés.

En una reflexión sobre el quehacer de la Gerontología, Cardoso (2010) observa que los adultos mayores que se encuentran desesperanzados y sin metas son aquellos que viven la vejez de una forma negativa, "Erikson lo reconoce como "despaire" o sea, ausencia de esperanza. También se refiere a que si una persona vive su vejez como experiencia negativa es que la experimenta como un estancamiento o regresión" (p. 87). En tal caso, se puede tomar como ejemplo el caso del esposo de Claire, quien ya no experimentaba movimiento en su vida, se encontraba en un periodo de estancamiento, pues visualizaba su vida como algo ya construido y concluido, no como un proceso en formación.

Para el esposo de Claire resulta sumamente difícil renunciar a ella, no por el hecho de que la ame o no, sino porque representa parte de la estabilidad alcanzada de ese mundo ya construido. No es el mismo caso para Andreas y Claire, quienes recordando su amor de juventud, se animan a experimentar nuevas cosas y se establecen nuevas metas, aunque saben que no les queda mucho tiempo de vida, no ven la muerte cercana como algo que les pueda impedir el experimentar, aprender y crecer.

Cardoso (2010) en su artículo pone en evidencia el dilema existente sobre cómo se visualiza la vejez, por un lado, existe la alternativa de visualizarlo como un auge, para esta posición se puede ver como ejemplo el caso de Claire y Andreas, quienes crecen y se sienten plenos en esta etapa. Por otro lado, se ve esta etapa como un declive o estancamiento, para este caso se puede observar el caso del esposo de Claire, quien considera inútil cambiar el estilo de vida que ya se posee, pues ya "se es viejo para hacer ciertas cosas", para él es increíble el hecho de que se pueda tener un amante a los 80 años, pues ya incluso para él el sexo también representa algo que no corresponde a su edad.

Siguiendo con lo anterior, se debe tener en cuenta que la visualización de la vejez como un declive no es algo que nazca de la nada, hay un papel preponderante de la sociedad en ese sentido, pues "la sociedad, con ciertos estereotipos (derivados de su entorno), ve que las personas adultas mayores ya no pueden acrecentarse y que, además, ni siquiera lo desean ya, y lo más grave es que ellos aceptan estos estereotipos" (Cardoso, 2010, p. 88). En vista de lo anterior, es necesario realizar un cambio que permita ver la etapa de la vejez 
como una etapa plena, donde se pueda hacer un recuento de lo logrado y ver qué otras cosas se desean alcanzar.

En ese sentido, interesa la cuestión de las representaciones sociales sobre la vejez, y en esa línea que Liliana Gastrón (2003) realiza una investigación sobre el tema, la cual nace a raíz de una anterior donde se observó que las maestras poseían y transmitían (a sus alumnos) estereotipos negativos sobre la vejez,

Concluimos entonces que en los mensajes transmitidos por ellas a los niños se reproducen tales concepciones erróneas sobre las personas de edad, y por lo tanto, la educación era un punto clave si se desean encarar acciones tendientes a buscar la inclusión social de la gente de cualquier edad sin discriminaciones (Gastrón, 2003, p. 183).

Las conclusiones de Gastrón (2003) apuntan a una clara diferenciación en la concepción de la vejez que va a depender de edad, género y lugar de procedencia. Cuenta el hecho de que existe una visión negativa de la vejez aún en personas de este grupo etario, unida a una negación de la pertenencia a dicho grupo. Esto se relaciona con los mecanismos de defensa utilizados, con mayor frecuencia en personas de edad adulta.

Schaie y Sherry (2003), por su parte, proponen un concepto de vejez que toma en cuenta muchos más aspectos, en este nuevo concepto también se hace referencia a la vivencia personal de la vejez, pues se hace hincapié en lo que puede significar la vejez, lo cual no va a ser igual en todas las personas,

La vejez puede ser un periodo de gran realización personal y puede proporcionar la oportunidad de implicarse en la exploración de opciones que antes no eran factibles por cuestiones familiares o laborales. El envejecimiento óptimo consiste en un proceso de optimización y compensación selectiva. Este proceso implica maximizar el apoyo interpersonal y ambiental (Schaie y Sherry, 2003, p. 112).

Para finalizar este apartado, se debe agregar que hay muchas cosas que se podrían vivir a plenitud en la vejez si se dejara de lado una visión negativa de dicha etapa. Es esa la razón del epígrafe, el ciclo vital, en general, posee una nostalgia constante por la etapa de desarrollo anterior, esto debido al proceso de cierre, sin embargo algunas personas, al llegar a la vejez, no superan esa etapa de nostalgia, se lamentan por la juventud perdida, sin notar las nuevas experiencias que se pueden tener al estar en una etapa que se caracteriza por una evaluación de todo lo alcanzado y la propuesta de nuevas experiencias.

\section{Sobre la vivencia de la muerte}

Y cuando llegue el día del último viaje, y esté al partir la nave que nunca ha de tornar, me encontraréis a bordo ligero de equipaje, casi desnudo, como los hijos del mar. (Machado, 1995, p. 33). 
La muerte cercana puede ser algo que infunda pavor en las personas adultas mayores, sin embargo también puede ser vista con tranquilidad como en el caso del epígrafe del poeta español Antonio Machado. De nuevo en la vivencia de este proceso también van a influir una multiplicidad de factores sociales, históricos, psicológicos, como por ejemplo la naturalidad con que se haya visto la muerte durante la vida.

Si se tuvo una vida plena, es posible que la muerte no sea vea como algo amenazante, sino más bien como la cúspide de un proceso vital. Para bien o para mal, la vida culmina con la muerte y ese es el destino patético del ser humano, al vivir una vida plena se posee menos nostalgia al saber que dicho proceso vital está cerca de su fin.

Pese a lo anterior, la muerte no es un proceso que se vea con naturalidad en la cultura occidental, "cuando los abuelos o alguna persona cercana mueren, se aparta a los niños para protegerlos de todo lo que tiene que ver con esa pérdida" (Schaie y Sherry, 2003, p. 565). Parece un tanto absurda esta cuestión de la protección, ¿protegerlos de qué? Quizá lo adecuado sería aprovechar el momento para acercar a los niños al conocimiento de un proceso natural, que tarde o temprano llegará y que lo óptimo sería que llegue por vejez y no de otra forma.

Según Schaie y Sherry (2003) existe un proceso en el cual lo que se desea es ocultar la muerte o lo feo, esto puede recordar el caso del padre de Siddhartha, quien con el afán de proteger a su pequeño lo tenía encerrado en su palacio, lejos del dolor, la enfermedad y la muerte. Sin embargo, el joven Siddhartha llega a conocer todo eso. Desde la Edad Media se construyen lugares donde se confina a las personas enfermas, y esta práctica continúa siendo muy común en nuestra sociedad, pocas son las personas enfermas o moribundas a las que se les permite morir en su casa.

Analizando la muerte del personaje Claire de la película Inocencia, se puede observar que es un proceso vivido por ella de forma plena, está haciendo algo que le agrada, y le agradó desde joven: escuchar a Andreas tocar el órgano, en ese momento se siente libre, plena, feliz, muere sola, escuchando el órgano que toca su amante, muere en una iglesia, lo cual resulta paradójico, pues durante el desarrollo de su vida no se ve que ella sea una persona muy cercana a dicha institución.

La época actual está llena de constantes paradojas, Schaie y Sherry (2003) apuntan una sobre la muerte, por un lado, hay una sobreexposición a la muerte por medio de los noticieros, las guerras, etc. Por otro lado, hay una obsesión por ocultarla y negarla. Sin embargo, Schaie y Sherry (2003) también apuntan que la muerte a la que se sobreexpone el ser humano es una sin contenido afectivo para él, lo cual hace que no se vea de forma amenazante.

De acuerdo con Cardoso (2006), una forma de negar la inminencia de la muerte es crear una rutina, "como una autodefensa los viejos se refugian en 
su medio ambiente habitual, en su rutina de cada día. Al llegar a viejos, las costumbres se convierten inconscientemente en tiranías" (p. 205). Esto puede ser notado en John (el esposo de Claire), como se mencionó antes, él cree que su vida ya está construida y no hay necesidad de movimiento de cambio, posee sus rutinas, un grupo de coro, un grupo de golf, su casa, el periódico, de vez en cuando cenar con una pareja de amigos y ya; eso es todo, no hay nada más que se pueda vivir, es su forma de verlo todo estable y con ello negar que hay una proximidad de muerte, es hasta que su esposa introduce un cambio, que él toma consciencia de ese tema.

Dentro del proceso de la vivencia de la muerte, hay un punto de suma importancia: la muerte del otro. Sobre este tema, Cardoso (2006) señala que entre las personas de la tercera edad puede ser vista de forma positiva, debido a que,

La muerte entre adultos, es un golpe fuerte entre sus coetáneos; entre los viejos no lo es tanto, "su insensibilidad confunde". Se diría que la muerte de los demás refuerza su alegría salvaje de "sentirse vivos" de haber sobrevivido (p. 205).

La aseveración anterior resulta un tanto injusta, pues es imposible que personas que tengan una conexión afectiva con alguien que muere piensen solamente en el hecho de que ellos sí han sobrevivido. Sin embargo, tal vez esa sensación sea algo que sí se experimente, pero que no sea externada por el hecho de que no es algo que, en esta sociedad, se vea bien.

Otra forma de verlo es la que proponen Schaie y Sherry (2003), quienes ven el proceso de la muerte del otro como algo que siempre va a afectar a la persona mayor, para la cual van a ser sumamente importantes las estrategias de afrontamiento que haya desarrollado a lo largo de la vida. Para Schaie y Sherry (2003) las personas se enfrentarán a un proceso de duelo (no exclusivo de esta etapa del desarrollo humano), pero que sí será vivido con mucha más ansiedad, debido a que se experimentará la sensación de haber sido abandonados.

Para las mujeres (y los hombres) mayores, la pérdida de la pareja significa el final de una larga vida en común y la desaparición de un futuro también común; la pérdida irrecuperable del compañero de sus vidas, de la persona a quien más querían y que más les quería, de alguien a quien cuidar y por quien ser cuidado; muchas veces también supone la pérdida de la independencia y/o del acostumbrado nivel de vida (Schaie y Sherry, 2003, p. 574).

No se puede apreciar en la película cómo enfrentan los personajes de Andreas y John la muerte de Claire, pero se puede presuponer que ambos estarán bastante impactados por la muerte de Claire, pues sentían por ella mucho cariño. En el caso de Andreas es perder el amor que ya había perdido una vez en su juventud. En el caso del esposo, también presupone una doble pérdida, pues recientemente es consciente de que ella ya no lo ama. 
Finalmente, un punto importante es la importancia que toma la religión o temas trascendentales en esta etapa (Schaie y Sherry, 2003; Cardoso, 2006). Pues al sentir que les es cercana la muerte se interesan por "el más allá" (¿qué hay después de la muerte?). Cardoso (2006) da una explicación a lo anterior cuando asevera que,

La demostración de la espiritualidad del alma humana y de la existencia de Dios, son los principales temas teológicos, ya que es preciso admitir que tenemos un alma, valemos lo que nuestros dioses. Si nuestros dioses son mortales, moriremos con ellos (p. 205).

Un ejemplo de dicha preocupación se puede encontrar en Andreas, quien al saber que podría estar enfermo y quizá con los días contados, se preocupa por la muerte, por la trascendencia de su yo, más que por la permanencia física en este mundo, lo cual resulta muy interesante. A pesar de eso, no abandona su posición agnóstica con respecto a la religión, Andreas parece enfrentarse a la muerte probable de forma tranquila como en el epígrafe de este apartado (el poema de Machado), él no está preocupado por la conservación de su cuerpo, sino de su yo (su pensamiento en palabras de Andreas).

\section{Sobre la vivencia de la sexualidad}

Le encenderás con el calor de la cima de miel que son tus pechos. Viento suave, tu alma animará su llama. (Azofeifa, 1994, p. 18)

La sexualidad ha sido un tema tabú en nuestra sociedad, hablar sobre sexualidad resulta impuro, pues igual que con la muerte resulta un tema que se niega y se oculta, casi siempre por puritanismos religiosos, pues se piensa que el único fin de la sexualidad es la procreación. En el 2004, Gustavo Garita publica un artículo en el que trata el tema de la sexualidad en la etapa de la vejez y mediana edad. Al hacer la revisión sobre los aspectos de orden fisiológico, concluye que los mismos no tienen incidencia en la nulidad de la sexualidad en la vejez, ya que los resultados de todos los estudios tomados en cuenta concluyen que es posible la vivencia de una sexualidad plena en dicha etapa (Garita, 2004).

Garita (2004) encuentra que las razones o temores que hacen negar la sexualidad por las personas de la tercera edad radican, por un lado, en el rechazo social, pues la práctica sexual por parte de personas de la tercera edad es estigmatizada socialmente. Por otro lado, se encuentran los temores como producto de la experiencia de vida, pues el emprender la sexualidad en la vejez implica un nuevo aprendizaje, un redescubrimiento del cuerpo, lo cual muchos no están dispuestos a emprender, debido a un temor al fracaso y encontrarse de frente 
con el hecho tangible de la vejez y el cambio producto de ella (Garita, 2004). Garita también hace hincapié en las diferencias de género y su incidencia en el tema de la sexualidad.

Al respeto de las diferencias de género, Hernández, Renteria y Sardiñas (2009) realizaron una investigación, cuyo objetivo era dilucidar las diferencia de género en la autopercepción de la sexualidad, en sus resultados apuntan que,

En el sexo femenino el mayor porcentaje no guarda ninguna relación entre sexualidad y enfermedad [...]; estos datos coinciden con lo planteado por diferentes autores que expresan que las limitaciones de la sexualidad se deben a una inadecuada información del paciente sobre sus posibilidades y no a las enfermedades presentes (Hernández, Renteria y Sardiñas, 2009, p. 7).

Pese a lo apuntado, al existir un incremento de la población adulta mayor, existe también un cambio en la concepción de sexualidad que se poseía antes, las mujeres y hombres mayores están viviendo de nuevo su sexualidad, este cambio es analizado por Dos Santos y Antonio Carlos (2008), quienes postulan que la sexualidad en la vejez es vista como una realidad incómoda, algo de lo que no se desea hablar, no por el hecho de que no exista, sino porque no se quiere aceptar.

La vivencia de la sexualidad en la vejez, posee matices diferentes de los que posee en etapas de la juventud, esto se nota claramente en la película Inocencia, Andreas y Claire vivían una sexualidad mucho más abierta en la juventud, esto cambia en su reencuentro en la vejez, debido a que se deben redescubrir y no poseen la misma fuerza que poseían en la juventud, sus cuerpos son distintos, sin embargo, ellos logran adecuarse a su nueva forma corporal y disfrutar de su expresión sexual, tal y como se anota en la siguiente cita.

El sexo y el amor en la vejez cambian el carácter explosivo y exuberante de la juventud, tomando la forma de la ternura, del cariño, del toque sutil, de la valorización de la sensibilidad de los pequeños gestos, respetando las diferencias de las manifestaciones del hombre y la mujer (Santos y Antonio Carlos, 2008, p. 35).

La cita rescata los cambios que se producen en la vivencia de la sexualidad con respecto a la etapa de juventud, sin embargo se considera innecesario destacar esa diferencia, lo que sí es importante es poner de manifiesto que sí hay una necesidad sexual en la vejez, que sí hay una vivencia de la misma. Si se observa el caso de Claire en relación con su esposo, se puede hacer notar que las necesidades sexuales de ella y el distanciamiento en el tema por parte de él, provocan frustración en ella. Hay una necesidad que ella no le transmite y que él, por su parte, niega o justifica su nulidad en la enfermedad cardíaca de ella.

Es claro el deseo sexual en ella en el momento en el que se masturba, no de una forma "explosiva y exuberante", pero lo hace porque siente la necesidad y el deseo de hacerlo. Después, podemos ver a Claire disfrutar ese placer vedado 
durante 20 años con su amigo de juventud: Andreas, quien también es consciente de que la sexualidad no acaba en la vejez, sino que se vive intensamente de una forma diferente.

Finalmente, la razón del epígrafe no obedece a su contenido por sí mismo, sino a la persona que escribió el poema: Isaac Felipe Azofeifa, intelectual nacional muy reconocido por su labor investigativa. Él empieza a escribir poesía erótica a la edad de 50 años, se apunta esta información como un dato más a favor de visualizar esa sexualidad en la vejez que hay tanto temor en reconocer.

\section{Conclusiones}

Gracias a todo lo revisado hasta el momento, se puede visualizar la necesidad de una mayor investigación sobre el envejecer, dejando de lado los estigmas imperantes en la sociedad respecto a esta población, los cuales se basan en la falacia de que los adultos mayores ya están cansados y no son productivos en la sociedad. El sistema capitalista en el que se inserta la sociedad actual refuerza estos estigmas, pues la evaluación de la productividad de una persona se hace en términos materiales sin tomar en cuenta aspectos como la sabiduría, la experiencia de vida y demás valores no materiales de los que son dueños indudables las personas de la tercera edad.

Finalmente, se puede articular a raíz de los plateamientos de este ensayo que el envejecer es una etapa que puede ser vivida con pasión y el disfrute por las cosas que nos gustaron durante toda la vida (música, poesía, literatura, ejercicio, sexualidad, etc.). La sexualidad puede ser reinterpretada dándole énfasis a aspectos como la ternura y el reconocimiento del nuevo cuerpo propio y el de la pareja. Las reflexiones sobre la muerte cercana pueden provocar una vivencia más íntima de la espiritualidad desde cualquier denominacion religiosa. Parece, pues, que la vivencia de la plenitud y el florecimiento de esta estapa se experimentará como tal de acuerdo a la actitud de cada persona. Dentro de esta vivencia son esenciales los procesos psicosociales y la historia personal de los individuos, si no se entiende esto, será imposible comprender el por qué para cada persona el envejecer se vive de manera diferente.

\section{Referencias bibliográficas}

Azofeifa, I. (1994). El don inefable. En: Antología poética. San José: Editorial Educa.

Cardoso, A. (2010). El movimiento, el tiempo y la vejez. Revista De La Facultad De Medicina De La UNAM, 53(2), 87-89. 
Cardoso, A. (2006). El viejo de ayer (5a parte) Vejez, religión, muerte y adaptabilidad. Revista de la Facultad de Medicina de la UNAM, 49(5), 205206.

Cox, P. (Director). (2000). Inocencia. [Película]. Australia-Bélgica.

Dos Santos, S., \& Antonio Carlos, S. (2008). Sexualidad en la vejez: ¿una realidad incómoda o una nueva realidad? (Spanish). Perspectivas En Psicología: Revista De Psicología y Ciencias Afines, 5(2), 28-36.

Fernández González, H. (2008). Envejecimiento. Medicina Universitaria, 10(41), 235.

Gastrón, L. (2003). Una mirada de género en las representaciones sociales sobre la vejez. La Aljaba, Segunda Época. Revista De Estudios De La Mujer, 81, 77-192.

Garita, G. (2004). Envejecimiento y sexualidad alrededor de la historicidad de su vivencia y sus determinaciones psicosocioculturales. Revista de Ciencias Sociales, 105(III), 59-79.

Hernández, M., Díaz, P., \& Llerenas, E. (2009). Estados clínicos y autopercepción de la sexualidad en ancianos con enfoque de género. Revista Cubana De Angiología Y Cirugía Vascular, 10(1/2), 1-9.

Machado, A. (1995). Retrato. En: Antología poética. Madrid: Alianza.

Schaie, K. W. \& Sherry L. Willis. (2003). Desarrollo adulto y envejecimiento. En: Psicología de la edad adulta y la vejez. España: Pearson Educación, S.A.

Schaie, K. W. \& Sherry L. Willis. (2003). La muerte y el proceso de morirse. Pérdida y duelo. En: Psicología de la edad adulta y la vejez. España: Pearson Educación, S.A.

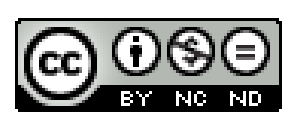

Este obra está bajo una licencia de Creative Commons ReconocimientoNoComercial-SinObraDerivada 4.0 Internacional. 